\title{
Atomic Sulfur Passivation Improves the Photoelectrochemical Performance of ZnSe Nanorods
}

\author{
Fei Huang ${ }^{1,2,3, *, \dagger}$, Jiajia Ning ${ }^{3,4,+}{ }^{-}$, Wei Xiong ${ }^{2,3}{ }^{-}$, Ting Shen ${ }^{1}$, Yanling Zhao ${ }^{2}$, \\ Jianjun Tian ${ }^{1}$, Ruiqin Zhang ${ }^{2,3}$ and Andrey L. Rogach ${ }^{3,4}$ \\ 1 Institute for Advanced Materials and Technology, University of Science and Technology Beijing, \\ Beijing 100083, China; ting_shen@sutd.edu.sg (T.S.); tianjianjun@mater.ustb.edu.cn (J.T.) \\ 2 Department of Physics, City University of Hong Kong, Hong Kong 999077, China; \\ weixiong4-c@my.cityu.edu.hk (W.X.); apzyl@cityu.edu.hk (Y.Z.); aprqz@cityu.edu.hk (R.Z.) \\ 3 Center for Functional Photonics (CFP), City University of Hong Kong, Hong Kong 999077, China; \\ jiajning@cityu.edu.hk (J.N.); andrey.rogach@cityu.edu.hk (A.L.R.) \\ 4 Department of Material Science and Engineering, City University of Hong Kong, Hong Kong 999077, China \\ * Correspondence: huangfei@ustb.edu.cn \\ $\dagger$ These authors contributed equally to this work.
}

Received: 23 April 2020; Accepted: 21 May 2020; Published: 31 May 2020

check for updates

\begin{abstract}
We introduced atomic sulfur passivation to tune the surface sites of heavy metal-free ZnSe nanorods, with a $\mathrm{Zn}^{2+}$-rich termination surface, which are initially capped with organic ligands and under-coordinated with Se. The $\mathrm{S}^{2-}$ ions from a sodium sulfide solution were used to partially substitute a 3-mercaptopropionic acid ligand, and to combine with under-coordinated $\mathrm{Zn}$ termination atoms to form a $\mathrm{ZnS}$ monolayer on the $\mathrm{ZnSe}$ surface. This treatment removed the surface traps from the ZnSe nanorods, and passivated defects formed during the previous ligand exchange process, without sacrificing the efficient hole transfer. As a result, without using any co-catalysts, the atomic sulfur passivation increased the photocurrent density of $\mathrm{TiO}_{2} / \mathrm{ZnSe}$ photoanodes from 273 to $325 \mu \mathrm{A} / \mathrm{cm}^{2}$. Notably, without using any sacrificial agents, the photocurrent density for sulfur-passivated $\mathrm{TiO}_{2} / \mathrm{ZnSe}$ nanorod-based photoanodes remained at almost $100 \%$ of its initial value after $300 \mathrm{~s}$ of continuous operation, while for the post-deposited $\mathrm{ZnS}$ passivation layer, or those based on $\mathrm{ZnSe} / \mathrm{ZnS}$ core-shell nanorods, it declined by $28 \%$ and $25 \%$, respectively. This work highlights the advantages of the proper passivation of II-VI semiconductor nanocrystals as an efficient approach to tackle the efficient charge transfer and stability of photoelectrochemical cells based thereon.
\end{abstract}

Keywords: photoelectrochemical cell; heavy metal-free photocatalyst; ZnSe nanorods; atomic sulfur passivation; $\mathrm{ZnS}$ monolayer

\section{Introduction}

It is ever important to establish efficient photocatalytic water splitting systems, in order to obtain clean and easily storable hydrogen fuels for solving energy and environment issues [1,2]. Compared with semiconductor powder-based photocatalytic water splitting systems, photoelectrochemical (PEC) cells can effectively suppress the backward reactions, thus enabling us to collect hydrogen more easily [3-5]. The photocatalyst is at the core of PEC cells, and thus extensive efforts have been devoted to the development of abundant, inexpensive, nontoxic, and efficient photocatalysts [6-12]. Among those, colloidal semiconductor nanocrystals (NCs), with a physical size smaller than the exciton Bohr radius, offer some useful properties as compared with bulk semiconductors [13-17]. Their valence and conduction band positions, and thus the redox potentials of photogenerated holes and electrons, can be adjusted on demand for a given material while tuning the particle size, due to 
the quantum confinement effect. The large surface area of the colloidal nanoparticles provides abundant surface reaction sites and promotes their contact with electron donors and/or acceptors in PEC cells. At the same time, this leads to a high ratio of under-coordinated surface termination atoms, which are usually passivated with organic capping ligands, mostly long-chain alkyl amines, or alkyl acids in the case of NCs synthesized in organic solvents [18-22]. Those termination atoms may lead to the formation of deep or shallow mid-gap states, which often increases the chance for nonradiative or thermal exciton dissipation [23-26]. For the colloidal semiconductor NCs to be applied in PEC, in order to promote charge transfer and facilitate their efficient loading on metal oxide substrates, their original long-chain alkyl-based ligands are commonly exchanged by short chain bifunctional ligands, such as thioglycolic acid (TGA) or 3-mercaptopropionic acid (3-MPA) [27]. However, this ligand exchange process can easily introduce additional surface traps, causing inefficient charge carrier transfer, which then in turn results in the degradation of the anode materials and the overall PEC performance [28-30]. We note that it is also possible to employ II-VI NCs, which are directly synthesized in water, employing short ligands TGA or MPA, in order to achieve more efficient charge transfer at the interface [31-33]. However, the aqueous-based TGA or MPA-capped NCs still face a high ratio of surface termination atoms. Tailoring the surface states of semiconductor NCs is thus particularly important for improving the performance of PEC cells. One common method is the growth of a shell of a wider bandgap material on the NC surface to construct the so-called core-shell structures $[29,34,35]$. In the core-shell heterostructures, surface defects are normally situated at the outer surface of the shell, thus lowering the probability of trapping photogenerated charge carriers, which are generated in the core by the surface site. However, an improper shell thickness would hinder the charge carrier transport in core-shell NCs, while the lattice mismatch between the core and the shell materials may introduce defects at the core-shell interface, which would compromise the optoelectronic properties [36]. Another frequently applied method is the deposition of the metal chalcogenide (ZnSe or ZnSe) on an NC-based photoelectrode via a successive ionic layer adsorption and reaction (SILAR) or chemical bath deposition (CBD) [37,38]. This approach was rather successful in improving photocurrent density due to the reduced amount of surface defects.

Other than the Cd- or Pb-based NCs, which contain heavy metals [39,40], ZnSe is a II-VI semiconductor material with a direct bandgap of $2.7 \mathrm{eV}$ and suitable conduction band edge position located at around $-1.1 \mathrm{~V}$ vs. NHE $(\mathrm{pH}=0)$, which has been regarded as a promising heavy metal-free photocatalyst for water splitting $[17,41]$. In view of the superior charge carrier separation in elongated nanorods (NRs), which can enhance PEC performance, we applied ZnSe NRs and suggested an atomic sulfur passivation method to passivate the surface sites on ZnSe nanorods (NRs) and to improve the performance of the respective PEC cells, which was accomplished by dipping ZnSe NR-based photoanodes into a sodium sulfide solution. The $\mathrm{Zn} / \mathrm{Se}$ atomic ratio in the initial ZnSe NRs has been determined to be 1.4:1 by inductively coupled plasma-atomic emission spectrometry (ICP-AES), meaning that they possess a $\mathrm{Zn}^{2+}$-rich termination surface. X-ray photoelectron spectroscopy (XPS) analysis indicated that upon the treatment with sodium sulfide, $\mathrm{S}^{2-}$ ions substituted a large fraction of surface ligands and combined with the $\mathrm{Zn}$ termination atoms to form a $\mathrm{ZnS}$ monolayer. Without using any sacrificial reagents and/or co-catalysts, this atomic sulfur passivation method increased the photocurrent density of a $\mathrm{TiO}_{2} / \mathrm{ZnSe} \mathrm{NR}$ photoanode from $273 \mu \mathrm{A} \mathrm{cm}^{-2}$ to $325 \mu \mathrm{A} \mathrm{cm}^{-2}$ as compared with the same photoanode without passivation. Furthermore, after atomic sulfur passivation, the photoanode showed no obvious decline in photocurrent density after $300 \mathrm{~s}$ of continuous operation, while the photoanodes with a post-deposited ZnS passivation layer, or those based on $\mathrm{ZnSe} / \mathrm{ZnS}$ core-shell NCs, exhibited photocurrent density decays of $28 \%$ and $25 \%$, respectively. Photoelectrochemical characterization has shown that an improved charge transfer and a suppressed charge recombination was achieved with the aid of $\mathrm{S}^{2-}$ passivation. 


\section{Experimental Section}

\subsection{Chemicals}

Zinc acetate dihydrate (>99\%), selenium (powder, 99.5\%, 100mesh), 1-dodecanethiol (1-DDT, 98.0\%), 1-octadecene (ODE, 90\%), and hexane (99\%, anhydrous) were purchased from Sigma-Aldrich (St. Louis, MO, USA). Oleylamine (OLA, approximate C18 content 80-90\%) was purchased from Arcos (NY, USA). 3-mercaptopropionic acid (3-MPA, >90\%, Sigma Aldrich), sodium hydroxide ( $\mathrm{NaOH}, 98 \%$, Sigma Aldrich), titanium oxide $\left(\mathrm{TiO}_{2}\right.$, Degussa, Corporation, Essen, Germany, P25), $\alpha$-terpineol $\left(\mathrm{C}_{10} \mathrm{H}_{8} \mathrm{O}, 96 \%\right.$, Sigma Aldrich), ethyl cellulose $\left(\left[\mathrm{C}_{6} \mathrm{H}_{7} \mathrm{O}_{2}\left(\mathrm{OC}_{2} \mathrm{H}_{5}\right)_{3}\right]_{\mathrm{n}}, 48.0-49.5 \%(\mathrm{w} / \mathrm{w})\right.$ as ethoxyl, Sigma Aldrich), zinc acetate dihydrate $\left(\mathrm{Zn}(\mathrm{AC})_{2} \cdot 2 \mathrm{H}_{2} \mathrm{O}, 98.0 \%\right.$, Alfa Aesar, Haverhill, MA, USA), sodium sulfate $\left(\mathrm{Na}_{2} \mathrm{SO}_{4}, 98.0 \%\right.$, Alfa Aesar), hydrochloric acid ( $\mathrm{HCl}, 37 \%$, Sigama Aldrich), methanol $\left(\mathrm{CH}_{3} \mathrm{OH}, \geq 99.5 \%\right.$, Sigma Aldrich), and ethanol $\left(\mathrm{CH}_{3} \mathrm{CH}_{2} \mathrm{OH}, \geq 99.5 \%\right.$, Decon Labs, King of Prussia, PA, USA) were directly used without further purification. Ultrapure deionized water was used for the preparation of all aqueous solutions.

\subsection{Synthesis of ZnSe NRs}

The synthesis was carried out using standard airless techniques on a vacuum/dry argon gas Schleck line system. Zinc acetate dihydrate (219.51 mg, $1 \mathrm{mmol})$, OLA (5.0 mL) and ODE (5.0 mL) were first added into a three-neck flask; then the mixture was degassed, heated to $90{ }^{\circ} \mathrm{C}$ and kept at $90{ }^{\circ} \mathrm{C}$ with the vacuum pump running for $1 \mathrm{~h}$. The reaction mixture was then heated to $220^{\circ} \mathrm{C}$, and $1.0 \mathrm{~mL}$ of selenium/(OLA $(0.7 \mathrm{~mL})+1-\mathrm{DDT}(0.3 \mathrm{~mL}))$ solution $(1.0 \mathrm{M})$ was injected; the mixture was quickly heated to $240{ }^{\circ} \mathrm{C}\left(5^{\circ} \mathrm{C} / \mathrm{min}\right)$ and kept at $240{ }^{\circ} \mathrm{C}$ for $60 \mathrm{~min}$. The resulting solution was mixed with $5.0 \mathrm{~mL}$ of hexane, and the reaction product was precipitated by adding ethanol, followed by centrifugation and re-dispersion in toluene.

\subsection{Synthesis of ZnSe/ZnS Core/Shell NRs}

In order to form core/shell ZnSe/ZnS NRs, after the growth of ZnSe NRs at $240{ }^{\circ} \mathrm{C}$ for 60 min with the presence of 1-DDT as described in the synthesis of ZnSe NRs, $3.0 \mathrm{~mL}$ of zinc oleate in OLA and ODE (1 M) was injected at $240{ }^{\circ} \mathrm{C}$ at the amount of $5 \mathrm{~mL} / \mathrm{h}$. The reaction mixture was kept at $240{ }^{\circ} \mathrm{C}$ for 60 min to grow ZnS shell on ZnSe NRs. It should be noted that, in this reaction, 1-DDT was employed as a sulfur source without injection of any additional $S$ precursors.

\subsection{Ligand Exchange on $\mathrm{ZnSe} N \mathrm{NR}$, and Fabrication of $\mathrm{TiO}_{2} / \mathrm{ZnSe} \mathrm{NR}$-Based Photoanodes}

OAm and 1-DDT ligands on ZnSe NRs were partially exchanged for 3-MPA by adding $90 \mu \mathrm{L}$ of 3-MPA to $40 \mathrm{~mL} \mathrm{ZnSe} \mathrm{NRs} \mathrm{in} \mathrm{toluene,} \mathrm{and} \mathrm{adjusting} \mathrm{the} \mathrm{pH}$ to 10 with $30 \% \mathrm{NaOH}$. After stirring for $30 \mathrm{~min}$, the original ligands were partially exchanged by 3-MPA. Then, $40 \mathrm{~mL}$ water was added to the above solution to extract the 3-MPA-capped water-soluble ZnSe NRs. After purification by several cycles of precipitation, the 3-MPA-capped ZnSe NRs were dissolved in $1 \mathrm{~mL}$ water. $\mathrm{A} \mathrm{TiO} / \mathrm{ZnSe}$ photoanode was made by drop casting the above $\mathrm{ZnSe} \mathrm{NR}$ solution onto mesoporous $\mathrm{TiO}_{2}$ substrate, and keeping it for $3 \mathrm{~h}$ at $30^{\circ} \mathrm{C}$; then the film was rinsed by water and methanol and dried. A mesoporous $\mathrm{TiO}_{2}$ film was made by a doctor blading method. $\mathrm{TiO}_{2}$ paste was first made by mixing $0.6 \mathrm{~g} \mathrm{P} 25 \mathrm{TiO}_{2}$ particles, $2.1 \mathrm{~g}$ alpha-terpilenol and $0.3 \mathrm{~g}$ ethyl cellulose using ethanol; it was doctor-bladed onto FTO glass, following by sintering at $500{ }^{\circ} \mathrm{C}$ for $30 \mathrm{~min}$ in air.

\subsection{Atomic Sulfur Passivation of ZnSe NRs-Based Photoanodes}

The photoanodes were dipped into a $0.1 \mathrm{M} \mathrm{Na}{ }_{2} \mathrm{~S} \cdot 9 \mathrm{H}_{2} \mathrm{O}$ solution for different durations $(2,5,7$, and $15 \mathrm{~min}$ ) followed by rinsing with methanol and drying. 
2.6. Depositing ZnS Layer on ZnSe NRs-Based Photoanodes by the Successive Ionic Layer Adsorption and Reaction (SILAR) Method

$\mathrm{A} \mathrm{TiO} / 2 / \mathrm{ZnSe}$ photoanode was immersed into a $0.1 \mathrm{MZn}\left(\mathrm{NO}_{3}\right)_{2} \cdot 6 \mathrm{H}_{2} \mathrm{O}$ solution for $1 \mathrm{~min}$, then rinsed with methanol and dried. This followed by dipping into $0.1 \mathrm{M} \mathrm{Na}_{2} \mathrm{~S} \cdot 9 \mathrm{H}_{2} \mathrm{O}$ solution for another 1 min to permit the formation of a $\mathrm{ZnS}$ monolayer. The procedure was repeated several times to control the thickness of the deposited ZnS layer. The deposition sequence has been also turned around for comparison.

\subsection{Characterization}

Transmission electron microscopy (TEM) and high-resolution TEM (HRTEM) measurements were performed on a JEOL 2100F microscope (Tokyo, Japan) at an accelerating voltage of $200 \mathrm{kV}$, with a field emission gun as the electron source. The morphology of the films was characterized by scanning electron microscope (SEM, JSM-7000, JEOL). The compositional EDX analysis and elemental mapping were carried out by EDX integrated in SEM. Powder X-ray diffraction (XRD) patterns were obtained using $\mathrm{Cu} \mathrm{K} \alpha$ radiation on a Bruker D2 machine (Karlsruhe, Germany). Inductively coupled plasma atomic emission spectroscopy (ICP-AES) was done on PerkinElmer Optima 8000 (Waltham, MA, USA). X-ray photoelectron spectroscopy (XPS) was performed on an Thermo Fisher Scientific ESCALAB 250 (Waltham, MA, USA). Optical absorption spectra were collected on a Cary 50 spectrophotometer (Santa Clara, CA, USA). Transient photocurrent density was measured on an CHI 660 electrochemical workstation (Shanghai, China) under AM 1.5 simulated sunlight with a power density of $100 \mathrm{~mW} \mathrm{~cm}^{-2}$. Electrochemical impedance spectroscopy (EIS) and Mott-Schottky (MS) plot were carried out using a $\mathrm{CHI} 660$ electrochemical workstation to investigate the electronic and ionic processes.

\section{Results and Discussion}

Heavy metal-free ZnSe NRs were produced via the hot-injection method with the assistance of oleyl amine (OAm) and 1-dodecanethiol (1-DDT) ligands, following a recently established synthetic procedure [42] (see Supporting Information (SI) for details). Transmission electron microscopy (TEM) images shown in Figure 1a demonstrate the rather uniform size of these ZnSe NRs. From the high resolution TEM (HRTEM) image in Figure $1 \mathrm{~b}$, the NRs are $2.8 \pm 0.2 \mathrm{~nm}$ in diameter and $8.0 \pm 2.0 \mathrm{~nm}$ in length (aspect ratio approx. 3). The marked lattice distance of $0.33 \mathrm{~nm}$ corresponds to (111) planes of the zinc-blende $\mathrm{ZnSe}$. The cubic zinc-blende phase has been also confirmed by the X-ray diffraction (XRD) pattern provided in Figure 1c.

To apply the ZnSe NRs to PEC cells, we deposited them on a mesoporous $\mathrm{TiO}_{2}$ film to construct ZnSe NR-based photoanodes. A short-chain ligand of 3-MPA with bifunctional groups (-SH and $-\mathrm{COOH}$ ) was employed to partially substitute the original long-chain ligands OLA and 1-DDT via an ex situ ligand exchange process, to facilitate charge transfer through the photoanode. The bifunctional 3-MPA ligand also served as an anchor to bind NRs to the surface of the $\mathrm{TiO}_{2}$ film [43]. Figure $1 \mathrm{~d}$ shows the UV-vis absorption spectra of the ZnSe NRs before and after the ligand exchange. The bandgap of the bulk ZnSe is $2.7 \mathrm{eV}$, which corresponds to the light absorption edge of $460 \mathrm{~nm}[44,45]$. The ZnSe NRs possess a diameter of $\sim 2.8 \mathrm{~nm}$, smaller than the Bohr exciton radius ( $3.7 \mathrm{~nm}$ ), and thus exhibit a quantum confinement effect [46]. The first excitonic peak and the light absorption onset of the as-synthesized ZnSe NRs are thus located at 380 and $404 \mathrm{~nm}$, respectively. After the ligand exchange process, both the first excitonic peak and the light absorption edge showed an $8 \mathrm{~nm}$ red shift. Such a red-shift likely has two possible causes. Firstly, as proposed and discussed in literature, such a red-shift can be attributed to the strong coupling between ZnSe NRs and MPA ligands [28,47,48]. Secondly, the purification of the ZnSe NRs during the ligand exchange process could also lead to a slight red-shift in the light absorption, due to the removal of surface ligands and the exposure of surface defects [49]. As already discussed in the introduction, such electron trapping states may become detrimental to the charge transfer process in PEC cells [29]. 
(a)

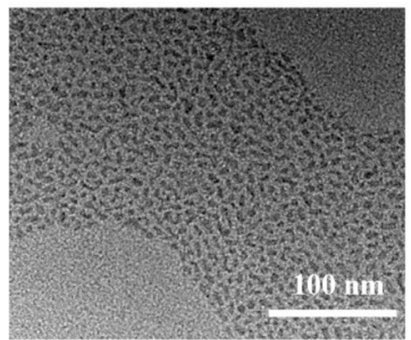

(d)

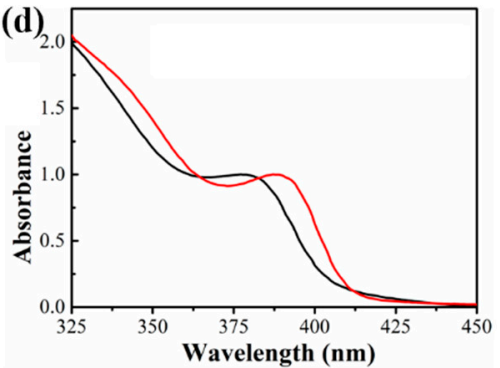

(b)
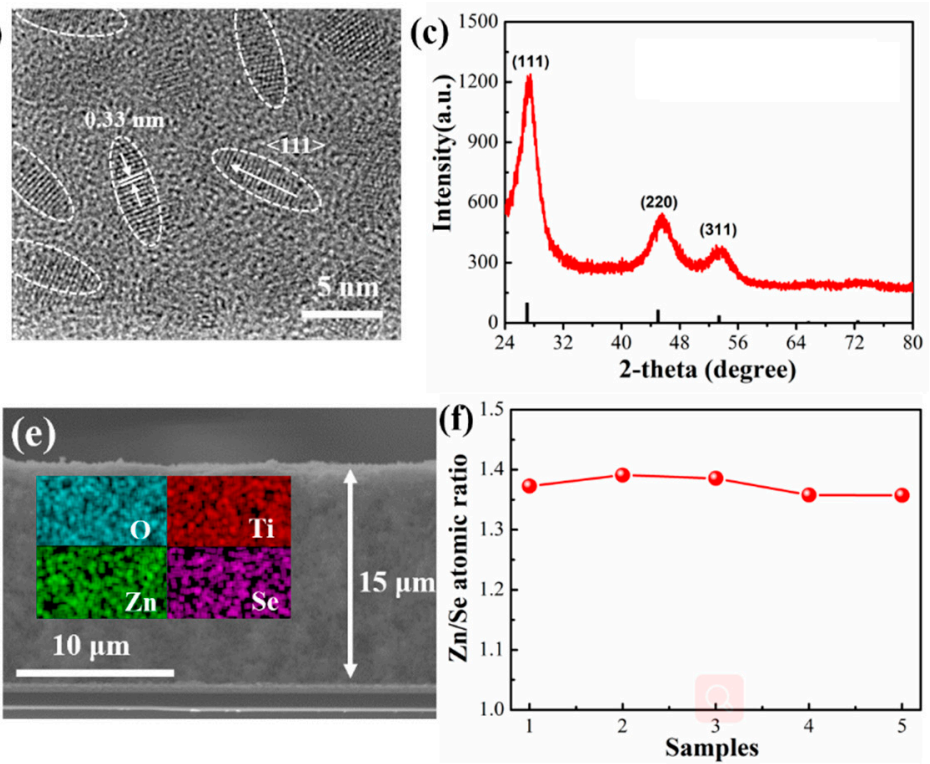

Figure 1. (a) TEM and (b) HRTEM images of ZnSe NRs. (c) XRD pattern of ZnSe NRs (in red); the line pattern in black gives the reflexes of the bulk zinc-blende ZnSe (JCPDS No. 37-1463). (d) UV-vis absorption spectra of ZnSe NRs before (black) and after (red) 3-MPA ligand exchange. (e) Cross-sectional SEM image of the $\mathrm{TiO}_{2} / \mathrm{ZnSe} \mathrm{NR}$ film, with elemental distribution maps of $\mathrm{O}, \mathrm{Ti}, \mathrm{Zn}$, and Se elements on its cross section provided as a colored inset. (f) $\mathrm{Zn} / \mathrm{Se}$ atomic ratio for the $\mathrm{ZnSe} N R s$ (five samples were tested) determined by ICP-AES.

Figure S1 shows the surface morphology of the mesoporous $\mathrm{TiO}_{2} / \mathrm{ZnSe} \mathrm{NR}$ photoanode. Its cross-sectional SEM image (Figure 1e) shows that the thickness of the $\mathrm{TiO}_{2}$ mesoporous film is approx. $15 \mu \mathrm{m}$. The elemental distribution maps of $\mathrm{O}, \mathrm{Ti}, \mathrm{Zn}$, and Se on the cross section reveal the uniform distribution of $\mathrm{ZnSe} \mathrm{NRs}_{\text {on }} \mathrm{TiO}_{2}$. Figure S2 compares the UV-vis spectra of the $\mathrm{TiO}_{2}$ and $\mathrm{TiO}_{2} / \mathrm{ZnSe}$ NR films. After immobilizing $\mathrm{ZnSe} \mathrm{NRs}$ on the $\mathrm{TiO}_{2}$ film, the light absorption intensity was significantly enhanced, and the absorption onset extended from $380 \mathrm{~nm}$ to $420 \mathrm{~nm}$, further confirming the successful loading of ZnSe NRs. ICP-AES was applied to determine the atomic ratio of $\mathrm{Zn}$ to Se in the NRs (Figure 1f), which was found to be approx. 1.4:1, despite of the same molar ratio of Zn and Se precursors (1:1) used in their synthesis. The $40 \%$ excess of $\mathrm{Zn}$ is thought to be surface termination atoms, which are coordinated to the ligands and under-coordinated with Se. Such a high percentage of surface termination atoms would bring the existence of charge trapping states, which may block the charge extraction and thus diminish the PEC performance $[26,50]$.

Aiming at passivating the surface states, we have suggested an atomic sulfide passivation method, as schematically illustrated in Figure 2. According to the previously presented data from HRTEM, $\mathrm{XRD}$, and ICP-AES, ZnSe NRs consist of a stoichiometric ZnSe core with $<111>$ orientation and a $\mathrm{Zn}$-terminated surface. Before the ligand exchange, the $\mathrm{Zn}$ termination atoms on the surface of $\mathrm{ZnSe}$ NRs are coordinated with the long-chain ligands 1-DDT and OAm, which are partially replaced by the short-chain ligand 3-MPA after the ligand exchange [51-53]. Both the unsaturated Zn termination atoms and the surface trap states brought by ligand exchange may detrimentally influence charge transfer and lead to the accumulation of holes on the ZnSe NRs, thus resulting in their photocorrosion. To eliminate these surface states, we dipped the ZnSe NR-based photoanodes into a sodium sulfide solution to allow the coordination of $\mathrm{S}^{2-}$ with the surface $\mathrm{Zn}$ termination atoms and formation of a monolayer of $\mathrm{ZnS}$. During this surface reaction, some short-chain 3-MPA ligands may become detached without sacrificing the efficient contact between the $\mathrm{NRs}_{\text {and }} \mathrm{TiO}_{2}$ film, as will be discussed later. 


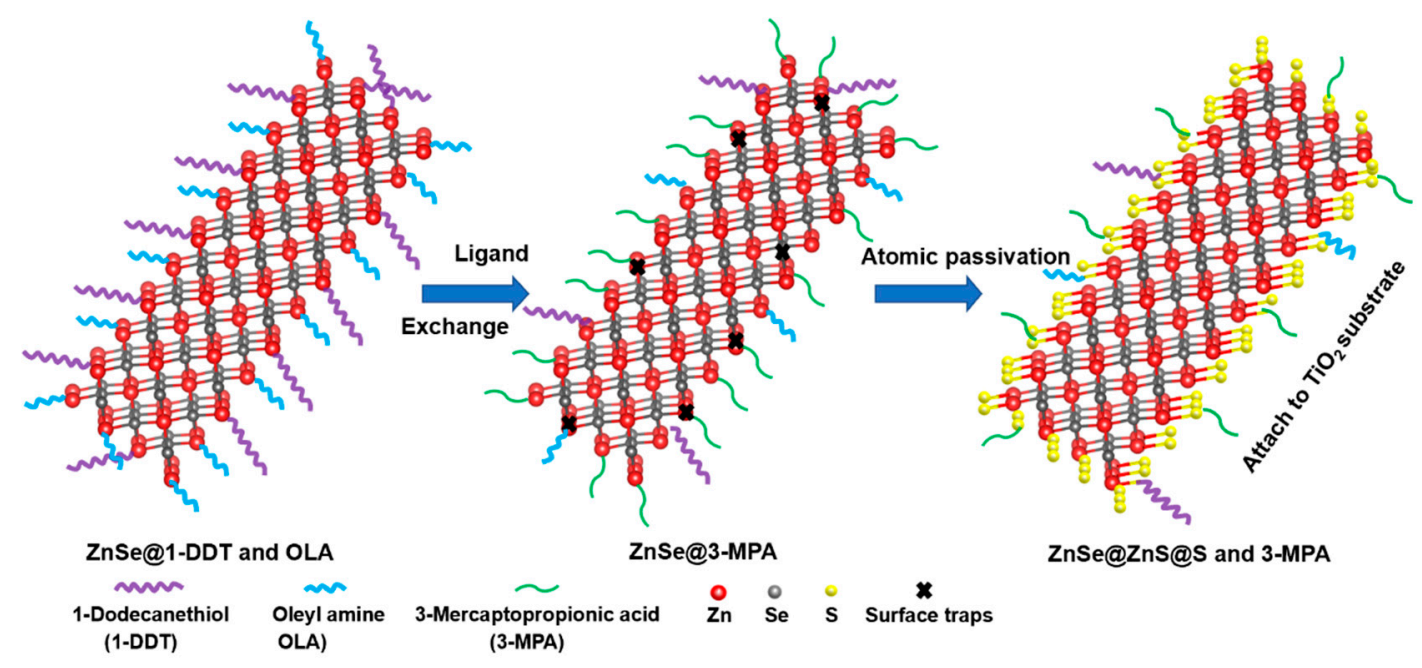

Figure 2. Schematic illustration of the surface configuration of ZnSe NRs during the 3-MPA ligand exchange and the subsequent atomic sulfur passivation by $\mathrm{Na}_{2} \mathrm{~S}$.

To evaluate the effect of the atomic sulfur passivation, we examined the transient photocurrent density of $\mathrm{TiO}_{2} / \mathrm{ZnSe} \mathrm{NR}$ photoanodes produced using various passivation durations of $0,2,5,7$, and $15 \mathrm{~min}$ (denoted as $\mathrm{TiO}_{2} / \mathrm{ZnSe} / \mathrm{S}$ - $x \mathrm{~min}$, where $x$ represents the time of the sulfur passivation treatment) without adding any sacrificial reagents and/or co-catalysts upon light illumination (see Figure $3 \mathrm{a}$ and Figure S3). For the mesoporous $\mathrm{TiO}_{2}$ photoanode on its own, the photocurrent density was $80 \mu \mathrm{A} \mathrm{cm}^{-2}$ (Figure S3), which increased to $273 \mu \mathrm{A} \mathrm{cm}{ }^{-2}$ after loading the ZnSe NRs (Figure 3a). However, a rather slow photo-response and poor stability of photoanodes were observed: the photocurrent density reached a peak of $275 \mu \mathrm{A} \mathrm{cm} \mathrm{c}^{-2}$ in almost $50 \mathrm{~s}$, which lasted for less than $100 \mathrm{~s}$, and then gradually decreased by $18 \%$ in only $200 \mathrm{~s}$ (Figure 3a). Such a slow photo-response and poor stability suggest that the charge extraction and transfer are not optimal for the non-passivated $\mathrm{ZnSe}$ NR-based photoanodes. Figure $3 \mathrm{~b}$ summarizes the dependence of the photocurrent density and photocurrent density retention of $\mathrm{TiO}_{2} / \mathrm{ZnSe} \mathrm{NR}$ photoanodes on the atomic sulfur passivation time. Upon increasing the atomic sulfur passivation durations, the photocurrent density underwent an increase to reach the highest value of $325 \mu \mathrm{A} \mathrm{cm}^{-2}$ when the passivation time was $5 \mathrm{~min}$. The further increase of passivation time above $5 \mathrm{~min}$ resulted in a decrease in the photocurrent density even though the stability was well maintained. Finally, the photocurrent density decreased by $32.3 \%\left(220 \mu \mathrm{A} \mathrm{cm}^{-2}\right)$ at the atomic sulfur passivation time of $15 \mathrm{~min}$. The linear sweep voltammetry (LSV) curves of the $\mathrm{TiO}_{2} / \mathrm{ZnSe}$ NR photoanodes passivated for 0, 5, and $15 \mathrm{~min}$ are shown in Figure 3c. Compared with the sample without atomic sulfur passivation, the $\mathrm{TiO}_{2} / \mathrm{ZnSe} / \mathrm{S}-5 \mathrm{~min}$ sample showed an improved photocurrent density, while the $\mathrm{TiO}_{2} / \mathrm{ZnSe} / \mathrm{S}-15$ min sample exhibited a decreased one, which further certified the optimal sulfur passivation time being $5 \mathrm{~min}$.

Figure $3 \mathrm{~d}$ illustrates the influence of the atomic sulfur passivation on the light harvesting capacity of $\mathrm{TiO}_{2} / \mathrm{ZnSe}$ NR photoanodes. The $\mathrm{TiO}_{2} / \mathrm{ZnSe} / \mathrm{S}-5$ min sample shows a slightly increased light absorption intensity compared with $\mathrm{TiO}_{2} / \mathrm{ZnSe}-0 \mathrm{~min}$, which can be due to the formation of a $\mathrm{ZnS}$ monolayer on the surface [54]. We note that for the sample passivated for $15 \mathrm{~min}$, the light absorption intensity decreased because of the detachment of some $\mathrm{ZnSe} \mathrm{NRs} \mathrm{from} \mathrm{the} \mathrm{TiO}_{2}$ surface, which could be corroborated by the data of the XPS analysis presented further below. 

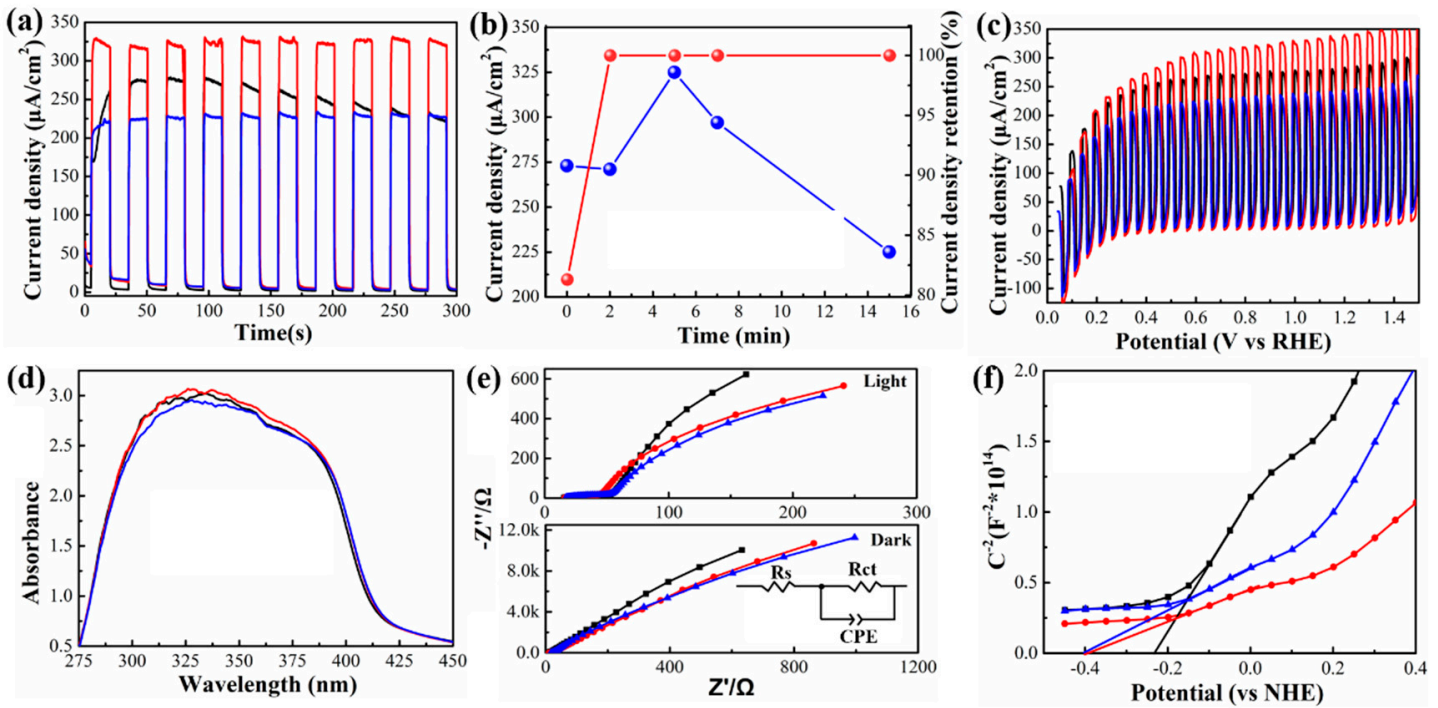

Figure 3. (a) Transient photocurrent density of $\mathrm{TiO}_{2} / \mathrm{ZnSe} \mathrm{NR}$ photoanodes with atomic sulfur passivation for $0 \mathrm{~min}$ (black), $5 \mathrm{~min}$ (red), and $15 \mathrm{~min}$ (blue). (b) Dependence of the photocurrent density (blue) and photocurrent density retention (red) of $\mathrm{TiO}_{2} / \mathrm{ZnSe} N \mathrm{NR}$ photoanodes on the duration of the atomic sulfur passivation (data points are at 0, 2, 5, 7, and $15 \mathrm{~min}$ ). (c) Light-chopped linear sweep voltammetry curves, (d) UV-vis absorption spectra, (e) electrochemical impedance spectroscopy curves under one sun illumination (AM 1.5 G) (inset: the equivalent circuit) and in the dark condition, and (f) Mott-Schottky plots of $\mathrm{TiO}_{2} / \mathrm{ZnSe}$ NR photoanodes passivated for $0 \mathrm{~min}$ (black), $5 \mathrm{~min}$ (red), and $15 \mathrm{~min}$ (blue). The intercepts of the Mott-Schottky plots represent the flat band potential of the photoanodes.

To obtain further insights into the effects of the atomic sulfur passivation, electrochemical impedance spectroscopy (EIS) under the illumination of an air mass 1.5 global (AM 1.5 G) solar simulator and under dark conditions was performed (see Figure 3e; an equivalent circuit model is shown in the inset). After the atomic sulfur passivation, the $\mathrm{TiO}_{2} / \mathrm{ZnSe}$ NR photoanodes exhibited much smaller charge transfer resistance $\left(\mathrm{R}_{\mathrm{ct}}\right)$, indicating a more efficient charge transfer process [55]. Figure $3 \mathrm{f}$ provides the Mott-Schottky plots for the $\mathrm{TiO}_{2} / \mathrm{ZnSe} \mathrm{NR}$ photoanodes generated from the space charge capacitance values [56-58]. Positive slopes of all three curves indicate the $n$-type semiconductor characteristic of photoanodes. The flat band potentials of the photoanodes were estimated from the intercepts of the Mott-Schottky plots. Both the flat band potentials of the $\mathrm{TiO}_{2} / \mathrm{ZnSe} / \mathrm{S}-5 \mathrm{~min}$ and $\mathrm{TiO}_{2} / \mathrm{ZnSe} / \mathrm{S}-15$ min samples were located at $\sim-0.4 \mathrm{eV}$, more negative than $-0.23 \mathrm{eV}$ for the $\mathrm{TiO}_{2} / \mathrm{ZnSe}-0$ min sample, which implies a more efficient thermodynamic driving force in the photoreduction process and a more efficient charge carrier injection.

XPS analysis was conducted to reveal the evolution of chemical states of the ZnSe NRs upon atomic sulfur passivation. Figure 4a displays the high-resolution XPS spectra of Se, which could be fitted into $3 d \mathrm{~d} 3 / 2$ and $3 \mathrm{~d} 5 / 2$ peaks [56]. With an increase in passivation time, the Se peaks slightly shifted to the lower energy region, and the peak position of $3 \mathrm{~d} 5 / 2$ became closer to $53.7 \mathrm{eV}$ (belonging to $\mathrm{ZnSe}$ ) [56], thus indicating a weakened surface effect on Se as a result of sulfur passivation. Figure $4 \mathrm{~b}$ shows the high-resolution $\mathrm{S}$ spectra of the $\mathrm{TiO}_{2} / \mathrm{ZnSe} \mathrm{NR}$ photoanodes passivated for 0,5 and $15 \mathrm{~min}$. In consideration of the fact that the $S 2 p$ peaks and Se $3 p$ peaks are located in the same region, all XPS spectra were first fitted into two Se $3 p$ peaks (shown by the green lines). The binding energies of the $\mathrm{S} 3 p$ peaks can be divided into $3 \mathrm{p} 3 / 2$ and 3 p $1 / 2$ peaks. For the $\mathrm{TiO}_{2} / \mathrm{ZnSe}-0$ min photoanode, the XPS spectrum for $S$ could be fitted by two peaks, while, for the $\mathrm{TiO}_{2} / \mathrm{ZnSe}-5$ min and $\mathrm{TiO}_{2} / \mathrm{ZnSe}-15$ min photoanodes, the XPS spectra for $S$ could be represented by four peaks. The $3 p 3 / 2$ and $3 p 1 / 2$ peaks located at $\sim 163 \mathrm{eV}$ and $\sim 164.2 \mathrm{eV}$ belong to the $\mathrm{S}$ bond in the 3-MPA ligands ( $H-S-)$, while the $3 \mathrm{p} 3 / 2$ and $3 \mathrm{p} 1 / 2$ peaks located at $\sim 160 \mathrm{eV}$ and $\sim 161.2 \mathrm{eV}$ can be assigned to the $\mathrm{S}$ bond in $\mathrm{ZnS}$ $(S-)$ [54]. By integrating the area under the fitted peaks, we found out that $S$ originated entirely from the 
H-S- ligands for the $\mathrm{TiO}_{2} / \mathrm{ZnSe}-0$ min photoanode without atomic sulfur passivation. For the sample passivated for $5 \mathrm{~min}$, the intensity ratio of H-S-:S- became 15:85 and changed to 5:95 after a 15 min passivation. The decreased ratio of H-S-:S- upon increasing passivation time indicates that the S2ions from the sodium sulfide solution gradually exchanged some of the surface ligands and combined with the under-coordinated Zn termination atoms on the ZnSe NRs' surface to form a ZnS monolayer. When the atomic passivation time was $15 \mathrm{~min}$, the amount of the 3-MPA remaining on the surface became rather low, which inevitably weakened the linkage between the $\mathrm{ZnSe}$ NRs and the $\mathrm{TiO}_{2}$ surface, resulting in the detachment of some $\mathrm{ZnSe} \mathrm{NRs}$, which can explain the decreased light absorption intensity of the $\mathrm{TiO}_{2} / \mathrm{ZnSe}-15$ min sample, as shown in Figure $3 \mathrm{~d}$, and the decreased photocurrent density with an increase in the atomic passivation time above $5 \mathrm{~min}$. High-resolution XPS spectra of the $\mathrm{Zn} 2 \mathrm{p}$ region, presented in Figure S4, also shows that the peaks shifted to the lower energy region after passivation, revealing the formation of $\mathrm{ZnS}$.
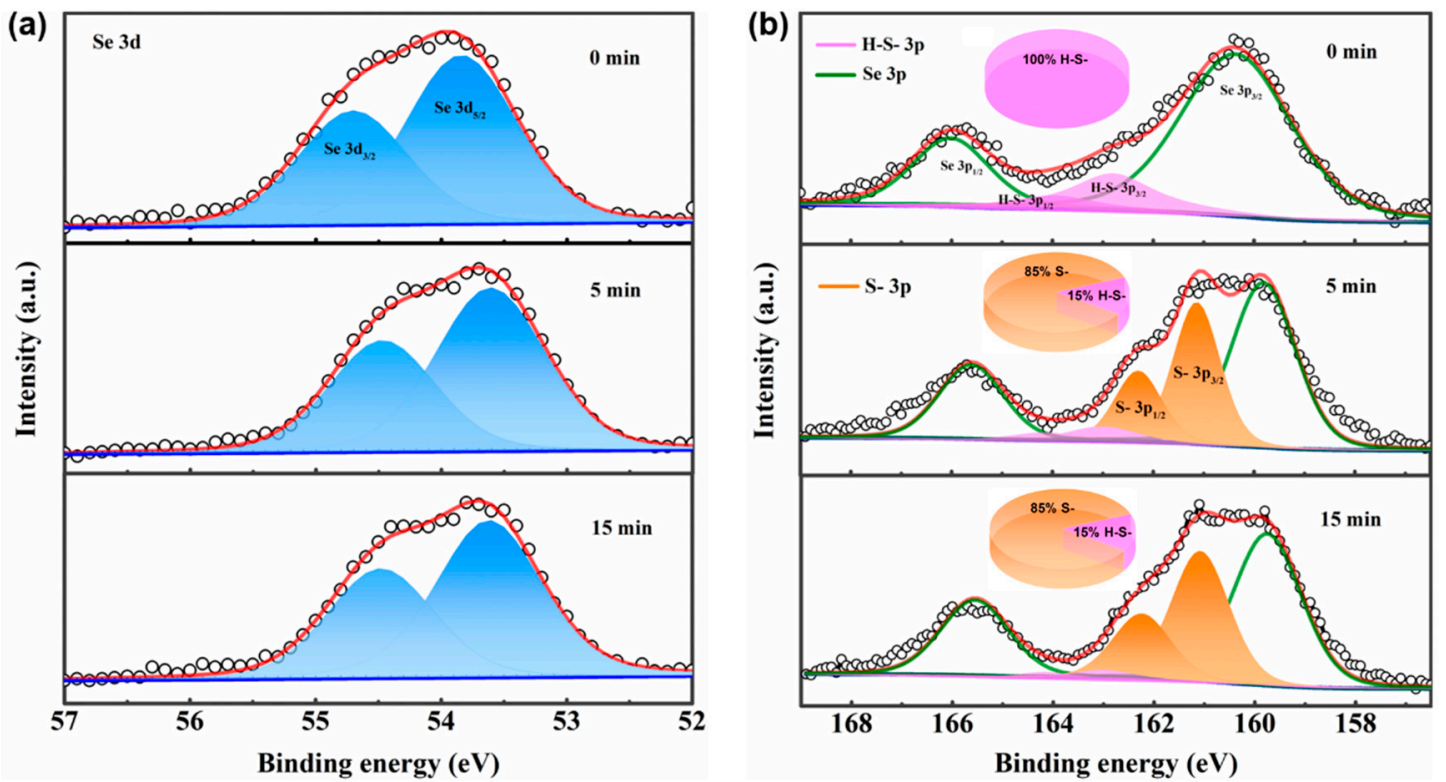

Figure 4. XPS spectra of (a) Se $3 d$ and (b) S $3 p$ of the $\mathrm{TiO}_{2} / \mathrm{ZnSe}$ NR photoanodes passivated with sulfur for 0,5 , and $15 \mathrm{~min}$. These XPS spectra offer insights into the chemical state evolution of Se and S bonds during the atomic sulfur passivation, which were made into pie charts to demonstrate the ratios of S from the 3-MPA ligand (H-S-) and in ZnS (S-). Raw intensity of Se and S (pancyclic line graphs) and peak sums of Se and $S$ (red lines) are also provided.

A comparison with other passivation methods, such as employing ZnSe/ZnS core-shell NRs, or the deposition of the ZnS layers using the SILAR method, was conducted to highlight the advantages of the atomic sulfur passivation method. ZnS shells can be directly grown on ZnSe NRs to construct core-shell ZnSe/ZnS nanorods (see Supporting Information for synthetic details), which were then deposited on mesoporous $\mathrm{TiO}_{2}$ films in a similar way as for ZnSe NRs. XRD patterns of ZnSe and $\mathrm{ZnSe} / \mathrm{ZnS}$ NRs are compared in Figure S5a; there was no change in the peak widths, but the diffraction peak positions slightly shifted to the higher angles, which indicated the successful growth of ZnS shell [59]. A red-shift in the UV-vis absorption peak (Figure S5b) and a significant improvement in the photoluminescence intensity (Figure S5c) further proved the formation of ZnSe/ZnS core-shell NRs [60]. Figure S5d compares the transient photocurrent densities of the $\mathrm{TiO}_{2} / \mathrm{ZnSe} \mathrm{NR}$ photoanodes without sulfur passivation and of the core-shell $\mathrm{ZnSe} / \mathrm{ZnS} \mathrm{NR}-$ based $\mathrm{TiO}_{2}$ photoanodes. The photocurrent density increased from $273 \mu \mathrm{A} \mathrm{cm}^{-2}$ for the former to $335 \mu \mathrm{A} \mathrm{cm}^{-2}$ for the latter, while the photocurrent density decreased to $242 \mu \mathrm{A} \mathrm{cm}^{-2}$ after $300 \mathrm{~s}$.

Besides, we also applied the frequently used SILAR method in order to deposit a ZnS passivation layer on top of $\mathrm{ZnSe} N R$-based $\mathrm{TiO}_{2}$ photoanodes (see Supporting Information for details). The transient 
photocurrent densities of photoanodes coated with $\mathrm{ZnS}$ passivation layers of different thicknesses and deposition sequences (from $\mathrm{Zn}^{2+}$ to $\mathrm{S}^{2-}$, or from $\mathrm{S}^{2-}$ to $\mathrm{Zn}^{2+}$ ) are shown in Figure $\mathrm{S} 6 \mathrm{a}, \mathrm{b}$, respectively. With an increase in the number of SILAR deposition cycles, the photocurrent density increased and reached its maximum of $342 \mu \mathrm{A} \mathrm{cm}{ }^{-2}$ after three cycles (the sequence from $\mathrm{Zn}^{2+}$ to $\mathrm{S}^{2-}$ ) and $375 \mu \mathrm{A} \mathrm{cm}{ }^{-2}$ after six cycles (the sequence from $\mathrm{S}^{2-}$ to $\mathrm{Zn}^{2+}$ ). A further increase in the number of SILAR deposition cycles led to a decrease in photocurrent density, because due to the more positive maximum valence band edge of $\mathrm{ZnS}$ compared to that of $\mathrm{ZnSe}$, the larger thickness of the $\mathrm{ZnS}$ layer would hinder the hole transfer from the NRs to the electrolyte [61].

Comparisons of the LSV curves (Figure 5a) and the transient photocurrent density (Figure 5b) for photoanodes prepared by three different methods revealed that although all three passivation methods of ZnSe NRs can improve the photocurrent density of $\mathrm{TiO}_{2}$ photoanodes, it was only the atomic sulfur passivation method which also improved the photoanode stability at the same time. The photocurrent density of the $\mathrm{TiO}_{2} / \mathrm{ZnSe} \mathrm{NR}$ photoanode passivated with atomic sulfur experienced almost no change for $300 \mathrm{~s}$ of the continuous operation, while the photocurrent densities of the photoanodes with ZnSe/ZnS core-shell NRs and with the post-deposited ZnS using the SILAR method declined by $28 \%$ and $25 \%$, respectively (Figure $5 \mathrm{~b}$ ). Such an improved stability is due to the more efficient electron and hole transfer, and thus reduced photo-corrosion of the photoanodes enabled by the atomic sulfur passivation strategy, which has been possible because of several favorable aspects inherent to this particular treatment. Firstly, the surface under-coordinated Zn atoms of ZnSe NRs were efficiently coordinated by sulfur during the passivation, without causing any imperfection on the surface or the interface. Secondly, the partial replacement of 3-MPA ligands by $\mathrm{S}^{2-}$ during the atomic sulfur passivation may have promoted carrier mobility, enabling the faster removal of holes, and thus reducing the degree of photo-corrosion [62].
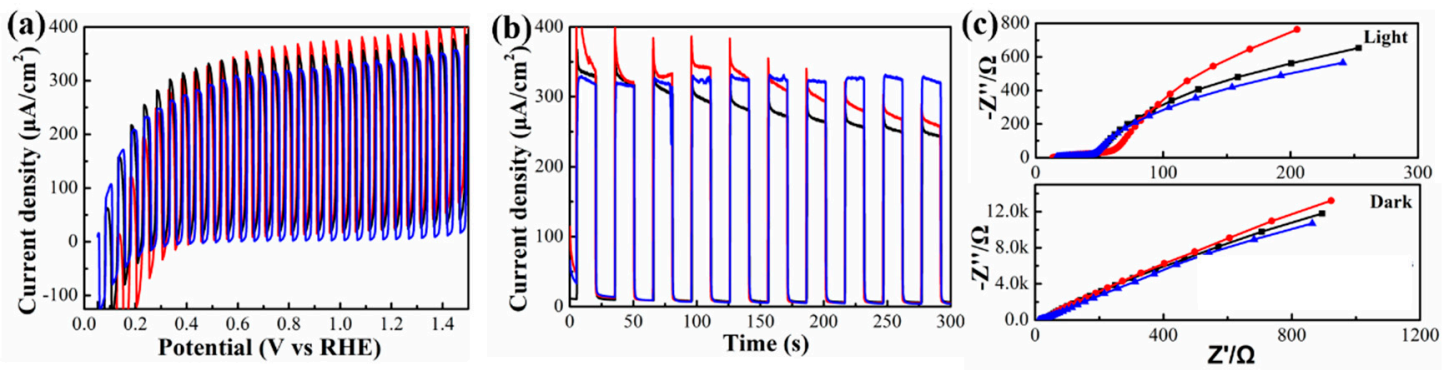

Figure 5. (a) Light-chopped LSV curves, (b) transient photocurrent density, and (c) EIS curves collected under light illumination and in the dark on the core-shell $\mathrm{ZnSe} / \mathrm{ZnS}$ NR-based $\mathrm{TiO}_{2}$ photoanodes (black), ZnSe NR-based $\mathrm{TiO}_{2}$ photoanodes with post-deposited ZnS using the SILAR method (red curves), and $\mathrm{TiO}_{2} / \mathrm{ZnSe} \mathrm{NR}$ photoanodes with sulfur atomic passivation for 5 mins (blue curves).

\section{Conclusions}

We have applied an atomic sulfur passivation strategy to treat the surface of ZnSe NRs used as components of $\mathrm{TiO}_{2} / \mathrm{ZnSe}$ photoanodes in PEC cells. As a result, without using any co-catalysts, the atomic sulfur passivation increased the photocurrent density of $\mathrm{TiO}_{2} / \mathrm{ZnSe}$ photoanodes from 273 to $325 \mu \mathrm{A} / \mathrm{cm}^{2}$. XPS study confirmed that $S^{2-}$ ions from a sodium sulfide solution can substitute the majority of 3-MPA ligands on the ZnSe NR surface and combine with the under-coordinated $\mathrm{Zn}$ termination atoms to form a ZnS monolayer. Compared with ZnSe/ZnS core-shell NRs or post-depositing a ZnS passivation layer using SILAR, atomic sulfur passivation is a more efficient treatment method to facilitate the charge carrier transfer, and thus reduce the photo-corrosion of ZnSe NRs. This work highlights the advantages of the proper passivation of II-VI semiconductor nanocrystals as an efficient approach to improve the charge transfer and stability of photoelectrochemical cells based thereon. 
Supplementary Materials: The following are available online at http://www.mdpi.com/2079-4991/10/6/1081/s1: Figure S1: SEM image of the mesoporous $\mathrm{TiO}_{2} / \mathrm{ZnSe}$ NRs photoanode; Figure S2: UV-vis absorption spectra of the $\mathrm{TiO}_{2}$ photoanode (black) and the $\mathrm{TiO}_{2} / \mathrm{ZnSe}$ NRs photoanode without applying sulfur passivation (red); Figure S3: Transient photocurrent density of the $\mathrm{TiO}_{2}$ photoanode (black), and the $\mathrm{TiO}_{2} / \mathrm{ZnSe}$ NRs photoanodes with an atomic sulfur passivation for $2 \mathrm{~min}$ (red) and $7 \mathrm{~min}$ (blue); Figure S4: Zn 2p XPS spectra of $\mathrm{TiO}_{2} / \mathrm{ZnSe}$ NRs photoanodes with atomic sulfur passivation for 0, 5, and $15 \mathrm{~min}$; Figure S5: (a) XRD patterns, (b) UV-vis absorption spectra, and (c) PL spectra of ZnSe NRs (black) and ZnSe/ZnS core/shell NRs (red). (d) Transient photocurrent density of $\mathrm{TiO}_{2}$ photoanodes modified with ZnSe NRs (black) and ZnSe/ZnS core/shell NRs (red); Figure S6: Transient photocurrent density of the $\mathrm{TiO}_{2} / \mathrm{ZnSe}$ NR-based photoanodes coated with $\mathrm{ZnS}$ passivation layers with different thickness and deposition sequence, (a) from $\mathrm{Zn}^{2+}$ to $\mathrm{S}^{2-}$ and (b) from $\mathrm{S2}^{-}$to $\mathrm{Zn}^{2+}$ using successive ionic layer adsorption and reaction (SILAR) method.

Author Contributions: F.H. and J.N. conducted experiments and wrote the paper. W.X., T.S. and Y.Z. helped to analyze data. J.T., R.Z., and A.L.R. revised and finalized the paper. All authors have read and agreed to the published version of the manuscript.

Funding: This research was funded by the National Science Foundation of China $(51902019,51961135107$, 51774034), Research Grants Council of Hong Kong SAR (CityU11305618, 11306219), Beijing Natural Science Foundation (2182039), the National Key Research and Development Program of China (2017YFE0119700), and by the Center for Functional Photonics of City University of Hong Kong. F.H. acknowledges the financial support through the "Hong Kong Scholars Program".

Conflicts of Interest: The authors declare no conflict of interest.

\section{References}

1. Chu, S.; Cui, Y.; Liu, N. The path towards sustainable energy. Nat. Mater. 2017, 16, 16-22. [CrossRef] [PubMed]

2. Mao, S.S.; Shen, S. Hydrogen production: Catalysing artificial photosynthesis. Nat. Photon. 2013, 7, 944. [CrossRef]

3. Abe, R.; Sayama, K.; Arakawa, H. Significant effect of iodide addition on water splitting into $\mathrm{H}_{2}$ and $\mathrm{O}_{2}$ over Pt-loaded $\mathrm{TiO}_{2}$ photocatalyst: Suppression of backward reaction. Chem. Phys. Lett. 2003, 371, 360-364. [CrossRef]

4. Walter, M.G.; Warren, E.L.; McKone, J.R.; Boettcher, S.W.; Mi, Q.; Santori, E.A.; Lewis, N.S. Solar water splitting cells. Chem. Rev. 2010, 110, 6446-6473. [CrossRef] [PubMed]

5. Wu, H.; Tan, H.L.; Toe, C.Y.; Scott, J.; Wang, L.; Amal, R.; Ng, Y.H. Photocatalytic and Photoelectrochemical Systems: Similarities and Differences. Adv. Mater. 2019, e1904717. [CrossRef] [PubMed]

6. Wang, H.; Zhang, L.; Chen, Z.; Hu, J.; Li, S.; Wang, Z.; Liu, J.; Wang, X. Semiconductor heterojunction photocatalysts: Design, construction, and photocatalytic performances. Chem. Soc. Rev. 2014, 43, 5234-5244. [CrossRef]

7. Wang, S.; Guan, B.Y.; Wang, X.; Lou, X.W.D. Formation of hierarchical $\mathrm{Co}_{9} \mathrm{~S}_{8} @ \mathrm{ZnIn}_{2} \mathrm{~S}_{4}$ heterostructured cages as an efficient photocatalyst for hydrogen evolution. J. Am. Chem. Soc. 2018, 140, 15145-15148. [CrossRef]

8. Guo, Y.; Chen, S.; Yu, Y.; Tian, H.; Zhao, Y.-L.; Ren, J.-C.; Huang, C.; Bian, H.; Huang, M.; An, L. Hydrogen-Location-Sensitive Modulation of the Redox Reactivity for Oxygen-Deficient $\mathrm{TiO}_{2}$. J. Am. Chem. Soc. 2019, 141, 8407-8411. [CrossRef]

9. Park, J.; Yang, W.; Tan, J.; Lee, H.; Yun, J.W.; Shim, S.G.; Park, Y.S.; Moon, J. Hierarchal Nanorod-Derived Bilayer Strategy to Enhance the Photocurrent Density of $\mathrm{Sb}_{2} \mathrm{Se}_{3}$ Photocathodes for Photoelectrochemical Water Splitting. ACS Energy Lett. 2019, 5, 136-145. [CrossRef]

10. Rahman, M.Z.; Batmunkh, M.; Bat-Erdene, M.; Shapter, J.G.; Mullins, C.B. p-Type BP nanosheet photocatalyst with AQE of $3.9 \%$ in the absence of a noble metal cocatalyst: Investigation and elucidation of photophysical properties. J. Mater. Chem. A 2018, 6, 18403-18408. [CrossRef]

11. Hao, L.; Kang, L.; Huang, H.; Ye, L.; Han, K.; Yang, S.; Yu, H.; Batmunkh, M.; Zhang, Y.; Ma, T. Surface-halogenation-induced atomic-site activation and local charge separation for superb $\mathrm{CO}_{2}$ photoreduction. Adv. Mater. 2019, 31, 1900546. [CrossRef] [PubMed]

12. Nguyen, V.-H.; Nguyen, B.-S.; Hu, C.; Nguyen, C.C.; Nguyen, D.L.T.; Nguyen Dinh, M.T.; Vo, D.-V.N.; Trinh, Q.T.; Shokouhimehr, M.; Hasani, A. Novel Architecture Titanium Carbide $\left(\mathrm{Ti}_{3} \mathrm{C}_{2} \mathrm{~T}_{\mathrm{x}}\right)$ MXene Cocatalysts toward Photocatalytic Hydrogen Production: A Mini-Review. Nanomaterials 2020, 10, 602. [CrossRef] [PubMed] 
13. Chen, H.M.; Chen, C.K.; Chang, Y.C.; Tsai, C.W.; Liu, R.S.; Hu, S.F.; Chang, W.S.; Chen, K.H. Quantum dot monolayer sensitized $\mathrm{ZnO}$ nanowire-array photoelectrodes: True efficiency for water splitting. Angew. Chem. Int. Ed. 2010, 49, 5966-5969. [CrossRef] [PubMed]

14. Sheng, W.; Sun, B.; Shi, T.; Tan, X.; Peng, Z.; Liao, G. Quantum dot-sensitized hierarchical micro/nanowire architecture for photoelectrochemical water splitting. ACS Nano 2014, 8, 7163-7169. [CrossRef]

15. Wu, H.L.; Li, X.B.; Tung, C.H.; Wu, L.Z. Sensitized Photocathodes: Recent Advances in Sensitized Photocathodes: From Molecular Dyes to Semiconducting Quantum Dots. Adv. Sci. 2018, 5, 1870023. [CrossRef]

16. Wang, Y.; Liu, X.; Liu, J.; Han, B.; Hu, X.; Yang, F.; Xu, Z.; Li, Y.; Jia, S.; Li, Z. Carbon quantum dot implanted graphite carbon nitride nanotubes: Excellent charge separation and enhanced photocatalytic hydrogen evolution. Angew. Chem. Int. Ed. 2018, 57, 5765-5771. [CrossRef]

17. Chen, D.; Zhang, H.; Li, Y.; Pang, Y.; Yin, Z.; Sun, H.; Zhang, L.C.; Wang, S.; Saunders, M.; Barker, E.; et al. Spontaneous Formation of Noble- and Heavy-Metal-Free Alloyed Semiconductor Quantum Rods for Efficient Photocatalysis. Adv. Mater. 2018, 30, e1803351. [CrossRef]

18. Moreels, I.; Lambert, K.; De Muynck, D.; Vanhaecke, F.; Poelman, D.; Martins, J.C.; Allan, G.; Hens, Z. Composition and size-dependent extinction coefficient of colloidal PbSe quantum dots. Chem. Mater. 2007, 19, 6101-6106. [CrossRef]

19. Morris-Cohen, A.J.; Frederick, M.T.; Lilly, G.D.; McArthur, E.A.; Weiss, E.A. Organic surfactant-controlled composition of the surfaces of CdSe quantum dots. J. Phys. Chem. Lett. 2010, 1, 1078-1081. [CrossRef]

20. Wei, H.H.; Evans, C.M.; Swartz, B.D.; Neukirch, A.J.; Young, J.; Prezhdo, O.V.; Krauss, T.D. Colloidal semiconductor quantum dots with tunable surface composition. Nano Lett. 2012, 12, 4465-4471. [CrossRef] [PubMed]

21. Reeves, K.G.; Schleife, A.; Correa, A.A.; Kanai, Y. Role of surface termination on hot electron relaxation in silicon quantum dots: A first-principles dynamics simulation study. Nano Lett. 2015, 15, 6429-6433. [CrossRef] [PubMed]

22. Yu, M.; Fernando, G.; Li, R.; Papadimitrakopoulos, F.; Shi, N.; Ramprasad, R. First principles study of CdSe quantum dots: Stability, surface unsaturations, and experimental validation. Appl. Phys. Lett. 2006, 88, 231910. [CrossRef]

23. Hines, D.A.; Kamat, P.V. Recent advances in quantum dot surface chemistry. ACS Appl. Mater. Interfaces 2014, 6, 3041-3057. [CrossRef] [PubMed]

24. Yazdani, N.; Bozyigit, D.; Vuttivorakulchai, K.; Luisier, M.; Infante, I.; Wood, V. Tuning Electron-Phonon Interactions in Nanocrystals through Surface Termination. Nano Lett. 2018, 18, 2233-2242. [CrossRef]

25. Subila, K.B.; Kishore Kumar, G.; Shivaprasad, S.M.; George Thomas, K. Luminescence Properties of CdSe Quantum Dots: Role of Crystal Structure and Surface Composition. J. Phys. Chem. Lett. 2013, 4, 2774-2779. [CrossRef]

26. Giansante, C.; Infante, I. Surface Traps in Colloidal Quantum Dots: A Combined Experimental and Theoretical Perspective. J. Phys. Chem. Lett. 2017, 8, 5209-5215. [CrossRef]

27. Li, W.; Zhong, X. Capping Ligand-Induced Self-Assembly for Quantum Dot Sensitized Solar Cells. J. Phys. Chem. Lett. 2015, 6, 796-806. [CrossRef]

28. Baker, D.R.; Kamat, P.V. Tuning the emission of CdSe quantum dots by controlled trap enhancement. Langmuir 2010, 26, 11272-11276. [CrossRef]

29. Zhu, H.; Song, N.; Lian, T. Controlling charge separation and recombination rates in CdSe/ZnS type I coreshell quantum dots by shell thicknesses. J. Am. Chem. Soc. 2010, 132, 15038-15045. [CrossRef]

30. Jeong, S.; Achermann, M.; Nanda, J.; Ivanov, S.; Klimov, V.I.; Hollingsworth, J.A. Effect of the thiol- thiolate equilibrium on the photophysical properties of aqueous CdSe/ZnS nanocrystal quantum dots. J. Am. Chem. Soc. 2005, 127, 10126-10127. [CrossRef]

31. Luan, C.; Vaneski, A.; Susha, A.S.; Xu, X.; Wang, H.-E.; Chen, X.; Xu, J.; Zhang, W.; Lee, C.-S.; Rogach, A.L. Facile solution growth of vertically aligned $\mathrm{ZnO}$ nanorods sensitized with aqueous $\mathrm{CdS}$ and CdSe quantum dots for photovoltaic applications. Nanoscale Res. Lett. 2011, 6, 340. [CrossRef]

32. Wang, H.; Luan, C.; Xu, X.; Kershaw, S.V.; Rogach, A.L. In situ versus ex situ assembly of aqueous-based thioacid capped CdSe nanocrystals within mesoporous $\mathrm{TiO}_{2}$ films for quantum dot sensitized solar cells. J. Phys. Chem. C 2012, 116, 484-489. [CrossRef] 
33. Hetsch, F.; Xu, X.; Wang, H.; Kershaw, S.V.; Rogach, A.L. Semiconductor nanocrystal quantum dots as solar cell components and photosensitizers: Material, charge transfer, and separation aspects of some device topologies. J. Phys. Chem. Lett. 2011, 2, 1879-1887. [CrossRef]

34. Sambur, J.B.; Parkinson, B.A. CdSe/ZnS core/shell quantum dot sensitization of low index $\mathrm{TiO}_{2}$ single crystal surfaces. J. Am. Chem. Soc. 2010, 132, 2130-2131. [CrossRef] [PubMed]

35. Abdellah, M.; Zidek, K.; Zheng, K.; Chábera, P.; Messing, M.E.; Pullerits, T. Balancing electron transfer and surface passivation in gradient $\mathrm{CdSe} / \mathrm{ZnS}$ core-shell quantum dots attached to ZnO. J. Phys. Chem. Lett. 2013, 4, 1760-1765. [CrossRef]

36. Baranov, A.; Rakovich, Y.P.; Donegan, J.; Perova, T.; Moore, R.; Talapin, D.; Rogach, A.; Masumoto, Y.; Nabiev, I. Effect of ZnS shell thickness on the phonon spectra in CdSe quantum dots. Phy. Rev. B 2003, 68, 165306. [CrossRef]

37. Huang, F.; Hou, J.; Zhang, Q.; Wang, Y.; Massé, R.C.; Peng, S.; Wang, H.; Liu, J.; Cao, G. Doubling the power conversion efficiency in $\mathrm{CdS} / \mathrm{CdSe}$ quantum dot sensitized solar cells with a ZnSe passivation layer. Nano Energy 2016, 26, 114-122. [CrossRef]

38. Huang, F.; Hou, J.; Wang, H.; Tang, H.; Liu, Z.; Zhang, L.; Zhang, Q.; Peng, S.; Liu, J.; Cao, G. Impacts of surface or interface chemistry of ZnSe passivation layer on the performance of CdS/CdSe quantum dot sensitized solar cells. Nano Energy 2017, 32, 433-440. [CrossRef]

39. Liu, B.; Li, X.-B.; Gao, Y.-J.; Li, Z.-J.; Meng, Q.-Y.; Tung, C.-H.; Wu, L.-Z. A solution-processed, mercaptoacetic acid-engineered CdSe quantum dot photocathode for efficient hydrogen production under visible light irradiation. Energy Environ. Sci. 2015, 8, 1443-1449. [CrossRef]

40. Trevisan, R.; Rodenas, P.; Gonzalez-Pedro, V.; Sima, C.; Sanchez, R.S.; Barea, E.M.; Mora-Sero, I.; Fabregat-Santiago, F.; Gimenez, S. Harnessing infrared photons for photoelectrochemical hydrogen generation. A PbS quantum dot based "quasi-artificial leaf". J. Phys. Chem. Lett. 2012, 4, 141-146. [CrossRef]

41. Kuehnel, M.F.; Creissen, C.E.; Sahm, C.D.; Wielend, D.; Schlosser, A.; Orchard, K.L.; Reisner, E. ZnSe Nanorods as Visible-Light Absorbers for Photocatalytic and Photoelectrochemical $\mathrm{H}_{2}$ Evolution in Water. Angew. Chem. Int. Ed. 2019, 58, 5059-5063. [CrossRef] [PubMed]

42. Ning, J.; Kershaw, S.V.; Rogach, A.L. Synthesis of Anisotropic ZnSe Nanorods with Zinc-Blende Crystal Structure. Angew. Chem. Int. Ed. 2020, 59, 5385-5391. [CrossRef] [PubMed]

43. Watson, D.F. Linker-assisted assembly and interfacial electron-transfer reactivity of quantum dot- substrate architectures. J. Phys. Chem. Lett. 2010, 1, 2299-2309. [CrossRef]

44. Hines, M.A.; Guyot-Sionnest, P. Bright UV-blue luminescent colloidal ZnSe nanocrystals. J. Phys. Chem. B 1998, 102, 3655-3657. [CrossRef]

45. Ning, J.; Liu, J.; Levi-Kalisman, Y.; Frenkel, A.I.; Banin, U. Controlling Anisotropic Growth of Colloidal ZnSe Nanostructures. J. Am. Chem. Soc. 2018, 140, 14627-14637. [CrossRef]

46. Adachi, S.; Taguchi, T. Optical properties of ZnSe. Phys. Rev. B 1991, 43, 9569. [CrossRef]

47. Koole, R.; Luigjes, B.; Tachiya, M.; Pool, R.; Vlugt, T.; de Mello Donegá, C.; Meijerink, A.; Vanmaekelbergh, D. Differences in cross-link chemistry between rigid and flexible dithiol molecules revealed by optical studies of CdTe quantum dots. J. Phys. Chem. C 2007, 111, 11208-11215. [CrossRef]

48. Kalyuzhny, G.; Murray, R.W. Ligand effects on optical properties of CdSe nanocrystals. J. Phys. Chem. B 2005, 109, 7012-7021. [CrossRef]

49. Gao, Y.; Peng, X. Photogenerated excitons in plain core CdSe nanocrystals with unity radiative decay in single channel: The effects of surface and ligands. J. Am. Chem. Soc. 2015, 137, 4230-4235. [CrossRef]

50. Fu, H.; Zunger, A. InP quantum dots: Electronic structure, surface effects, and the redshifted emission. Phys. Rev. B 1997, 56, 1496. [CrossRef]

51. Ji, X.; Copenhaver, D.; Sichmeller, C.; Peng, X. Ligand bonding and dynamics on colloidal nanocrystals at room temperature: The case of alkylamines on CdSe nanocrystals. J. Am. Chem. Soc. 2008, 130, 5726-5735. [CrossRef]

52. Anderson, N.C.; Hendricks, M.P.; Choi, J.J.; Owen, J.S. Ligand exchange and the stoichiometry of metal chalcogenide nanocrystals: Spectroscopic observation of facile metal-carboxylate displacement and binding. J. Am. Chem. Soc. 2013, 135, 18536-18548. [CrossRef]

53. Ip, A.H.; Thon, S.M.; Hoogland, S.; Voznyy, O.; Zhitomirsky, D.; Debnath, R.; Levina, L.; Rollny, L.R.; Carey, G.H.; Fischer, A.; et al. Hybrid passivated colloidal quantum dot solids. Nat. Nanotechnol. 2012, 7, 577-582. [CrossRef] 
54. Perry, D.; Waiskopf, N.; Verbitsky, L.; Remennik, S.; Banin, U. Shell Stabilization of Photocatalytic ZnSe Nanorods. Chem CatChem 2019, 11, 6208-6212. [CrossRef]

55. Liu, H.; Cheng, S.; Wu, M.; Wu, H.; Zhang, J.; Li, W.; Cao, C. Photoelectrocatalytic degradation of sulfosalicylic acid and its electrochemical impedance spectroscopy investigation. J. Phys. Chem. A 2000, 104, 7016-7020. [CrossRef]

56. Deng, Z.; Lie, F.L.; Shen, S.; Ghosh, I.; Mansuripur, M.; Muscat, A.J. Water-based route to ligand-selective synthesis of ZnSe and Cd-doped ZnSe quantum dots with tunable ultraviolet A to blue photoluminescence. Langmuir 2008, 25, 434-442. [CrossRef] [PubMed]

57. Orazem, M.E.; Tribollet, B. Electrochemical Impedance Spectroscopy; John Wiley \& Sons: Hoboken, NJ, USA, 2017.

58. Huang, M.; Zhao, Y.-L.; Xiong, W.; Kershaw, S.V.; Yu, Y.; Li, W.; Dudka, T.; Zhang, R.-Q. Collaborative enhancement of photon harvesting and charge carrier dynamics in carbon nitride photoelectrode. Appl. Cata. B Environ. 2018, 237, 783-790. [CrossRef]

59. Lad, A.D.; Mahamuni, S. Effect of ZnS shell formation on the confined energy levels of ZnSe quantum dots. Phys. Rev. B 2008, 78, 125421. [CrossRef]

60. Tamang, S.; Lincheneau, C.; Hermans, Y.; Jeong, S.; Reiss, P. Chemistry of InP nanocrystal syntheses. Chem. Mater. 2016, 28, 2491-2506. [CrossRef]

61. Huang, F.; Zhang, Q.; Xu, B.; Hou, J.; Wang, Y.; Massé, R.C.; Peng, S.; Liu, J.; Cao, G. A comparison of ZnS and ZnSe passivation layers on CdS/CdSe co-sensitized quantum dot solar cells. J. Mater. Chem. A 2016, 4, 14773-14780. [CrossRef]

62. Fan, X.B.; Yu, S.; Wang, X.; Li, Z.J.; Zhan, F.; Li, J.X.; Gao, Y.J.; Xia, A.D.; Tao, Y.; Li, X.B. Susceptible surface sulfide regulates catalytic activity of CdSe quantum dots for hydrogen photogeneration. Adv. Mater. 2019, 31, 1804872. [CrossRef] [PubMed]

(C) 2020 by the authors. Licensee MDPI, Basel, Switzerland. This article is an open access article distributed under the terms and conditions of the Creative Commons Attribution (CC BY) license (http://creativecommons.org/licenses/by/4.0/). 